\title{
Os Impactos do Racismo na Subjetividade do Jogador de Futebol Negro
}

\author{
Fábio Henrique Alves da Silva ${ }^{1}$ \\ ${ }^{1}$ Pontifícia Universidade Católica de Minas Gerais, \\ MG, Brasil.
}

\author{
Paula Ângela de Figueiredo e Paula ${ }^{1}$ \\ ${ }^{1}$ Pontifícia Universidade Católica de Minas Gerais, \\ MG, Brasil.
}

\begin{abstract}
Resumo: Temos visto sucessivos casos de racismo no esporte ao longo dos anos. Essa situação nos possibilita colocar em xeque a ideia de que há uma democracia racial no esporte, justificada pelo fato de que a projeção dos atletas independe de sua cor, pois aconteceria pelo mérito de seu esforço em treinar suas potencialidades. Escolhemos nos concentrar no futebol porque é o esporte que mais converge o sentimento nacionalista em nosso país. O objetivo principal desta pesquisa de conclusão do curso de Psicologia, foi o de investigar se há racismo no futebol brasileiro e se ele afeta a subjetividade dos negros brasileiros que trabalham no futebol. Visamos também investigar como a psicologia tem tratado o sofrimento causado pelo racismo na constituição das subjetividades dos negros. A metodologia escolhida foi a revisão bibliográfica que, percorre o que já foi publicado em livros, sites etc. Constatamos que os negros encontram espaços de trabalho quando são atletas, mas que sua participação é mínima como árbitros, treinadores ou gestores. A pesquisa revelou também que a própria psicologia demorou muito a se pronunciar sobre o sofrimento causado na constituição da subjetividade do negro. Utilizando as orientações técnicas do Centro de Referência em Psicologia e Politicas Publicas (Crepop) do Conselho Federal de Psicologia em 2017, pudemos concluir que, para tratar do sofrimento dos negros no esporte, é necessário ampliar a clínica, escutando o atleta em sua dimensão biopsicossocial.
\end{abstract}

Palavras-chave: Racismo, Esporte, Futebol, Subjetividade, Psicologia.

\section{The Impacts of Racism on the Subjectivity of Black Soccer Players}

\begin{abstract}
We have seen over the years successive cases of racism in sport. This situation makes us question the idea that there is a racial democracy in sport, justified by the fact that the projection of athletes is independent of their color, given that this is due to the merit of their efforts to train their potentialities. We chose to focus on soccer because it is the sport that most converges the feeling of nationalism in our country. We investigated in this research to conclude psychology course, if there is racism in Brazilian soccer and if it affects the subjectivity of Brazilian black people working in soccer. We also aim to investigate how Psychology has treated the suffering caused by racism in the constitution of black subjectivity. The chosen methodology was the bibliographic review that goes through what has already been published in books, websites and etc, The results show that black people find workspaces when they are still athletes, but their participation is minimal as referees, coaches or managers. The research also revealed that Psychology itself took a long time to take a stance on the suffering caused in the constitution of black subjectivity. Using the technical guidelines of the Reference Center in Psychology and Public Policy of the Federal Council of Psychology in 2017, we conclude that to address the suffering of black people in sports it is necessary to expand the clinic, listening to athletes in their bio-psycho-social dimension.
\end{abstract}

Keywords: Racism, Sport, Soccer, Subjectivity, Psychology. 


\title{
Los Impactos del Racismo en la Subjetividad de los Futbolistas Negros
}

\begin{abstract}
Resumen: Han ocurrido muchos casos de racismo en el deporte a lo largo de los años. Esta situación nos permite cuestionar la idea de que existe una democracia racial en el deporte, justificada por el hecho de que la proyección de los deportistas no depende de su color, sino del mérito de su esfuerzo en entrenar sus potenciales. Se eligió el fútbol porque es el deporte que más converge el sentimiento nacionalista en Brasil. El principal objetivo de esta investigatión para concluir el curso de Psicologia, fue investigar se hay racismo en el fútbol brasileño y si afecta la subjetividad de los brasileños negros que trabajan en lo fútbol. Además, se busca investigar cómo la psicología ha tratado el sufrimiento causado por el racismo en la constitución de subjetividades negras. Se optó por hacer una revisión bibliográfica en torno a lo que se ha publicado en libros, internet, etc. Se encontró que los negros encuentran espacios de trabajo cuando son deportistas, pero su participación se reduce a lo mínimo como árbitros, entrenadores o directivos. Además, se reveló que la propia psicología tardó mucho en pronunciarse sobre el sufrimiento causado en la constitución de la subjetividad negra. Con base en los lineamientos técnicos del Centro de Referencia en Psicología y Políticas Públicas del Consejo Federal de Psicología en 2017, se concluye que, para atender el sufrimiento de los negros en el deporte, es necesario ampliar la clínica, escuchando al deportista en su dimensión biopsicosocial.
\end{abstract}

Palabras clave: Racismo, Deporte, Fútbol, Subjetividad, Psicología.

\section{Introdução}

Este artigo é fruto da pesquisa de conclusão do curso de Psicologia da PUC-MG, em Betim, que se interessou em investigar o evidente racismo presente no esporte. Mesmo depois do movimento negro ter conseguido em 1989 a aprovação da Lei no 7.716, que define os crimes de racismo, bem como outras leis que foram implementadas para o mesmo fim como o Estatuto da Igualdade Racial de 2010 e a criação das cotas raciais, em 2012, ainda não vemos a população negra gozar dos direitos de cidadania. Nós partimos da hipótese de que não há democracia racial no esporte, um campo em que se justifica que a projeção dos atletas independe de sua cor, dado que acontece pelo mérito de seu esforço em treinar seu potencial. A escolha pelo futebol se deu por ser o esporte que mais converge o sentimento de nacionalismo em nosso país e o que mais nutre o sonho dos jovens de melhorar a vida. O objetivo principal foi o de investigar se há racismo no futebol brasileiro e se ele afeta a subjetividade dos negros brasileiros que trabalham no futebol. Visamos também investigar como a Psicologia tem tratado o sofrimento causado pelo racismo na constituição das subjetividades dos negros e, por fim, verificar o que a Psicologia do Esporte tem produzido sobre o assunto.

\section{Metodologia}

Para atingir nossos objetivos, escolhemos a revisão bibliográfica para levantar todas as referências encontradas sobre o racismo no futebol e sobre o que a Psicologia tem feito para tratar do sofrimento implicado na constituição da subjetividade dos jogadores negros no Brasil. O tipo de revisão foi a "narrativa", que não utiliza critérios explícitos e sistemáticos para a busca e análise crítica da literatura. A busca pelos estudos não precisa esgotar as fontes de informações, porque não aplica estratégias de busca sofisticadas e exaustivas. A seleção dos estudos e a interpretação das informações podem estar sujeitas à subjetividade dos autores e por isso é bem adequada à fundamentação teórica para artigos, dissertações, teses e trabalhos de conclusão de curso, como é o nosso caso. De acordo com Cervo e Bervian (2002), esse tipo de método busca referências de qualquer formato, ou seja, em livros, sites, revistas, vídeos, enfim, tudo que possa contribuir para um primeiro contato com o objeto de estudo investigado. Observa-se que não existe nessa opção um critério detalhado e específico para a seleção da fonte material, mas nós cuidamos de fazer o fichamento de todo o material encontrado, coletando dados que nos permitissem atingir nossos 
objetivos. Nós dividimos nosso artigo em três capítulos. O primeiro é destinado ao mapeamento do tema do racismo no futebol no Brasil e no mundo, para no segundo tratarmos da história singular da construção do racismo no Brasil. O terceiro capítulo é sobre a origem e história do futebol. Daí em frente visamos, no quarto capítulo, apresentar o conceito de identidade étnico racial e o quanto essa identidade está atrelada ao sofrimento psíquico. Por isso buscamos no quinto capítulo entender as orientações do conselho federal de psicologia (CFP) publicadas em 2017 e apresentar a defasagem da produção científica da Psicologia voltada ao esporte. No sexto e último capítulo, extraímos das orientações do CFP a necessidade de ampliar a clínica ao esporte, escutando a subjetividade de modo a contribuir para a erradicação do racismo no futebol.

\section{O panorama do racismo no futebol}

De acordo com Luccas (1998, p. 43), "o futebol é, e sempre foi, um espelho no qual estão refletidas as formas pelas quais as relações sociais se estabelecem", ou seja, ele é um fato social e não se resume a uma prática de lazer ou de entretenimento. $\mathrm{O}$ futebol profissional é um trabalho em que alguns negros ganham visibilidade, conquistam altos salários e viram celebridades. Embora os atletas se projetem socialmente, não temos uma estatística favorável de negros no comando do esporte. Além disso, temos visto, ao longo dos anos, sucessivos casos de racismo no esporte em todo o mundo, o que coloca em xeque a ideia de que há uma democracia racial nesse campo.

Dentro desse contexto, em um passado recente, torcedores e atletas se acostumaram a ver cenas como a do camaronês Samuel Eto’o. Em 2006, o então atacante do Barcelona ameaçou deixar o gramado em um jogo do Campeonato Espanhol sob o som de imitações de macacos feitas pela torcida do Zaragoza. Desde então, pouca coisa mudou.

Apesar da pressão feita pelas entidades responsáveis, atletas e torcedores continuaram a se manifestar de forma racista pelo mundo, especialmente no futebol. Curiosamente, o esporte mais popular do mundo é uma das modalidades na qual o negro só é valorizado por causa de seus atributos físicos e qualidade técnica, embora em situações de tensão e disputa brancos ainda possam se sentir superiores e serem mais valorizados. Isto deixa claro o preconceito, deixando a pessoa em situação de debilidade e sofrimento.
De acordo com Souza (2017) a desigualdade social no Brasil está muito atrelada à questão étnico-racial. Uma herança da escravidão particularmente sentida até os dias atuais é a naturalização dessa desigualdade. O conceito de democracia racial retira a escravidão da ótica da dominação pelo branco da elite econômica, escamoteando o preconceito e o racismo. Assim fica subentendido que há uma relação harmônica entre os diversos grupos étnicos que formam nossa gente. No esporte tem-se a tendência de minimizar expressões de racismo dizendo que é brincadeira, que a intenção não era de agredir o outro, embora quando uma pessoa é chamada de "macaco", ela seja rebaixada a uma posição de animalidade.

O racismo se faz presente de forma assustadora nas arquibancadas em manifestações de torcidas organizadas com ofensas raciais dirigidas contra juízes e atletas negros. No Brasil temos vários exemplos a partir do século XXI. Em 2006 o zagueiro Antônio Carlos, do Esporte Clube Juventude, foi suspenso após esfregar o braço em gesto de insulto contra o jogador negro Jeuvânio. Em agosto do ano de 2017, no jogo Flamengo x Botafogo, um torcedor foi preso depois que a família do jogador flamenguista Vinicius Junior sofreu insultos racistas durante o jogo. Em 2014, o jogador Tinga sofreu preconceito racial no Peru. A Confederação Brasileira de Futebol (CBF) desenvolveu a campanha "somos todos iguais", estendendo faixas durante os jogos buscando abolir as práticas racistas dos estádios.

Uma entrevista em 2017 para Breiller Pires, o colunista do El Pais, Marcelo Carvalho afirma que este tipo de campanha não tem muitos efeitos e que o preconceito racial está cada vez mais velado. Isso continua assim porque há falta de investigação e punição para quem tem esse tipo de conduta preconceituosa dentro do campo. Nessa entrevista, Marcelo Carvalho diz que nunca viu um dirigente da CBF condenar um ato de racismo no futebol.

Como raramente as pessoas são punidas por ofensas racistas, há uma inibição das vítimas, que não se sentem encorajadas a denunciarem. "Ainda permanece a ideia de que, no futebol, vale tudo. E de que a hostilidade preconceituosa 'faz parte do jogo', encarando o racismo como algo aceitável", analisa Marcel Diego Tonini, historiador e cientista social da Universidade de São Paulo (Pires, 2017).

Ex-atletas de futebol costumam seguir carreiras dentro dos clubes de futebol, seja como executivo, 
treinador, comissão técnica, dentre outros. Porém, no cenário dos grandes clubes brasileiros se observa que existe poucos negros nesses cargos. Skolaude (2015, p. 115) deixa a pergunta: "poderíamos interpretar esta triste realidade como uma forma velada de racismo ainda existente nos clubes brasileiros?"

Márcio Chagas relatou, em uma entrevista para UOL Esporte, sobre diversos episódios nos quais sofreu racismo, quando ainda era arbitro de futebol (Silva, 2019). Ele decidiu entrar com um processo no Superior Tribunal de Justiça Desportivo, depois de sofrer uma ofensa racista quando apitava uma partida de futebol. Porém foi desencorajado por jornalistas, alguns de seus conhecidos e até pela própria Federação Esportiva do Rio Grande do Sul que, até então, nunca tinha tido um arbitro negro.

Segundo o Conselho Federal de Psicologia, há uma discriminação institucional que é caracterizada por um conjunto de ações racistas no contexto organizacional ou da comunidade. E mesmo que não exista uma intenção de segregar, "tem impacto diferencial e negativo em membros de um grupo determinado" (Conselho Federal de Psicologia [CFP], 2017, p. 111). Por exemplo, são escassas as oportunidades de qualificação para empregados negros de maneira que eles não têm acesso a experiências que podem levá-los a um progresso de carreira. As oportunidades na nossa sociedade não são iguais, quebrando a ideia de meritocracia, deixando o negro sem recursos para ser competitivo para cargos de expressão.

$\mathrm{O}$ racismo dentro do futebol vem sendo naturalizado, justamente pela falta de políticas eficientes contra o preconceito racial dentro do esporte. Márcio Chagas, em uma conversa com o atacante Adriano Chuva, escutou que ele abandonou o futebol por ter sofrido racismo. Chagas publicou a conversa no site da UOL Esporte (2019), em que Adriano lhe disse que ele não podia imaginar o que lhes acontecia no centro da cidade. Os negros do time preferiam jogar fora de casa para não ser chamados de macaco em seu próprio estádio.

No futebol, existe uma tendência ao silenciamento quando o assunto é racismo. Muito jogador negro que passa por isso prefere ignorar os ataques temendo ter problemas na carreira se abrir a boca. Outro dia um jogador saiu de campo na Bolívia. Todos deviam fazer o mesmo, principalmente os medalhões (Silva, 2019, p. 1).
A discussão a respeito das relações étnico-raciais, racismo e políticas públicas deve estar na base da formação do psicólogo e demais profissionais da área da saúde em geral, desde sua graduação (Oliveira \& Nascimento, 2018). Essa é uma temática de extrema importância para a humanidade na contemporaneidade, onde as lutas e movimentos em prol da igualdade racial vem crescendo. "As lutas e vitorias do movimento negro protagonizam a luta comum por igualdade de outros grupos étnicos, culturais e sociais desprezados historicamente" (Oliveira \& Nascimento, 2018, p. 219).

Provavelmente o mito da democracia racial fez com que a psicologia clínica brasileira não cumprisse sua tarefa, "pois, em geral, psicólogos brasileiros mal se dão conta de como abordar a ironia hipócrita da sociedade brasileira que funda e organiza configurações emocionais" (Oliveira \& Nascimento, 2018, p. 222). De acordo com o autor, a categoria deveria se preocupar "com o desenvolvimento de práticas e ações que se comprometam a alterar os currículos de formação do psicólogo cuja base filosófica, social e política é extremamente precária”. Isso porque o sofrimento vindo dessas desigualdades produz modos de subjetivação que influenciam processos de construção de identidades sociais e coletivas. Na opinião de Oliveira e Nascimento (2018) tais configurações subjetivas e individuais decorrem em políticas ideológicas, princípios políticos normativos, formas de organização social que representam os modos subjetivados de compreender e interpretar o mundo, as organizações e si mesmo (Oliveira \& Nascimento, 2018, p. 218).

Como "as desigualdades sociais, diferentes em cada momento histórico, sempre encontraram reflexos no interior das relações promovidas pelo futebol" (Luccas, 1998, p. 48), vamos, no próximo item, apresentar sobre a constituição do racismo no Brasil para depois apresentar a história do futebol no país. Nossa intenção é a de mostrar o quanto a herança da escravidão tem determinado a subalternidade do negro em relação ao branco da elite econômica em todas as áreas da cultura, inclusive no esporte.

\section{A construção do racismo no Brasil}

No início do século XIX, a população brasileira era de 3.818 .000 pessoas, dentre elas, 1.930 .00 eram escravas. Existiam lugares no Brasil em que o número de escravos era superior ao de pessoas livres. Por volta de 1872, em Campinas, interior de São Paulo, 
a população livre era de 8.281 , enquanto a escravizada era de 13.685 pessoas. Já no estado do Rio de Janeiro, a população de origem africana representava $70 \%$ do número de habitantes (Albuquerque \& Filho, 2006).

Segundo Albuquerque e Filho (2006, p. 68), "a escravidão foi muito mais do que um sistema econômico". Ela modelou uma sociedade com condutas favoráveis a desigualdades sociais e raciais. Cada indivíduo foi ocupando seu espaço, existia quem mandava e quem obedecia. Os escravos eram o grupo mais oprimido da sociedade brasileira, eles não tinham nenhum direito, não podiam firmar contratos, possuir bens materiais e nem testemunhar contra casos de maus tratos. Era impossível escolher também o tipo de trabalho e o seu contratante. Ainda segundo o autor, "por isso, pode-se caracterizar o Brasil colonial e imperial como uma sociedade escravista, e não apenas uma que possuía escravos".

A sociedade se torna afirmativamente racista, já que os negros e mestiços, escravos, libertos e livres eram diminuídos em relação aos brancos. Dado toda essa contextualização, notamos na história que o racismo nasce a partir do tráfico negreiro e escravidão. Segundo Albuquerque e Filho (2006).

"Assim, ao se criar o escravismo estava-se também criando simultaneamente o racismo. Dito de outra forma, a escravidão foi montada para a exploração econômica, ou de classe, mas ao mesmo tempo ela criou a opressão racial" (Albuquerque \& Filho, 2006, p. 68).

Ainda seguindo a ideia do autor, a falta de direitos e a opressão social se mostram quando mesmo com um código favorável aos escravos, eles não possuíam poder algum. Apesar da legislação colonial permitir que escravos e livres denunciassem senhores cruéis às autoridades civis ou eclesiásticas, pouquíssimos senhores responderam perante os juízes por acusações de crueldade contra escravos. A maioria dos acusados terminou perdoada ou absolvida por juízes que, em geral, pertenciam à mesma classe dos senhores (Albuquerque \& Filho, 2006).

Dados do Instituto de Pesquisa Econômica Aplicada (Ipea), de 1995 a 2005, mostram que a situação social do negro no Brasil é terrível, seja quanto à expectativa de vida, seja quanto às condições materiais que reproduzem sua subalternidade, se compararmos com os brancos os índices de escolaridade, empregabilidade, vulnerabilidade social, entre outros.

\section{A história do futebol no Brasil}

De acordo com Maximo (1999, p. 183), o futebol no Brasil teve vários significados ao longo dos tempos. Ele já foi um passatempo da elite branca, foi "elemento de integração, paixão popular, profissão, meio de afirmação nacional, instrumento político, uma arte brasileira e finalmente um negócio milionário e global dentro do qual o Brasil representa importante papel”.

A história oficial do futebol começa com a importância de Charles Miller, nascido em São Paulo no ano de 1874 e filho de pais com nacionalidade inglesa e escocesa, que foi ainda criança estudar na Inglaterra. Ele voltou aos 20 anos, em 1894 (depois de ter tido experiência como jogador de futebol nas escolas inglesas pelas quais passou), transportando dois uniformes completos, uma bomba de ar, uma agulha e um pequeno livro contendo as regras básicas tais como haviam sido definidas poucos anos antes pela Federação Inglesa. Durante toda sua vida, ele se dedicou ao futebol de forma calorosa, foi jogador e árbitro, até vir a óbito no ano de 1953, quando estava com 79 anos de idade (Luccas, 1998).

Segundo Luccas (1998, p. 37) "o futebol nasce elitista e racista em 1894, seis anos após a Abolição da Escravatura", porque os únicos brasileiros que podiam participar eram os estudantes do College Mackenzine e seus familiares ingleses. Luccas alega que depois que o alemão Hans Nobiling organizou um time de futebol, a exclusividade dos britânicos foi rompida, surgindo gradualmente outros clubes de futebol no Brasil. No primeiro Campeonato Paulista em 1902, participaram cinco clubes, mas as equipes eram formadas por pessoas da elite paulista sem a participação de nenhum negro.

Com a popularização do futebol e o crescimento de campeonatos e times, alguns clubes formaram seus elencos com a participação de negros, mulatos e pessoas do povo que trabalhavam nas fábricas, visando maior competitividade (Luccas, 1998). Essa atitude não foi aceita de modo tranquilo e o Vasco da Gama, do Rio de Janeiro, por exemplo, quase foi penalizado com a exclusão do campeonato carioca por conquistar o título de 1920 com diversos jogadores negros no elenco (Maximo, 1998).

Outros times no Rio de Janeiro, tais como o América e o Bangu, também incluíram jogadores negros em seus planteis e, no estado de São Paulo, o Corinthians tinha em seu elenco jogadores negros e de origem popular. Saindo do eixo Rio-São Paulo, 
as coisas eram mais complicadas como, por exemplo, em Porto Alegre, onde o Grêmio Porto-Alegrense proibia em seus estatutos que negros vestissem sua camisa. "Essa proibição que só caducaria nos anos 50" (Maximo, 1999, p. 184).

Por causa dessa proibição, em 1910 os jogadores negros do Rio Grande do Sul/Brasil, como forma política de se manifestarem-se contra o racismo, criariam uma liga própria, nomeada de Liga da Canela Preta, "que formou times poderosos, com destaque para Primavera, Palmeiras, Primeiro de Novembro e Rio-Grandense" (Skolaude, 2015).

Em 1933 o futebol se tornou oficialmente uma profissão, porque um grande número de jogadores brasileiros ia jogar no exterior e isso já incluía negros e jogadores de origem popular. De acordo com Pimenta, citado por Luccas (1998), os clubes passaram a ser dirigidos por negociantes de grandes indústrias, que davam oportunidade ao trabalhador e ao jogador de futebol ter salários expressivos, uma renda extra e reconhecimento.

Para Maximo (1999, p. 85) "no Brasil, estranho que pareça, o avanço profissionalista teve como causa uma ideia conservadora". Esse regime teve uma aceitação maior de times de elite, que tinham seus elencos formados por sócio atletas e possuíam o direito de ir para a sede dos clubes. E estes mesmos clubes sofriam ameaças de exclusão em campeonatos por não possuírem jogadores negros em seus elencos. Profissionalizando o futebol, as equipes poderiam contratar jogadores de qualquer raça e classe social, sem precisar sujar o círculo social do clube quando se rejeita um jogador por sua cor ou condição social. "Não foi por acaso que as elites do Fluminense e do São Paulo estavam entre os líderes do movimento profissionalista" (Maximo, 1999, p. 185).

Durante o Estado Novo, época em que vigorava o governo de Getúlio Vagas, os jogadores negros e pobres começam a ter espaço dentro dos times de futebol. Mas era preciso ter bons níveis de habilidade, de forma que contribuísse para o status da equipe. A ideia de promover a Copa do Mundo em 1950 e a consequente construção dos estádios de futebol ajudou na abertura das portas dos times para a inclusão dos negros na elite no futebol.

A Copa do Mundo de futebol de 1950 foi um momento marcante com a derrota por 2 a 1 na partida final contra o Uruguai, dentro do Maracanã, porque "a responsabilização pelo fracasso recaiu sobre as costas de três atletas negros: Barbosa, Juvenal e Bigode", como se o negro carregasse em si o estigma do fracasso (Skolaude, 2015, p. 15).

Esse evento serviu como legitimação teórica das teorias raciais, isto é, o estigma do atleta negro enquanto fadado ao fracasso, como foi o caso de Barbosa, goleiro negro que defendeu a seleção brasileira naquele mundial. Desde então, constituiu-se no imaginário popular a concepção de que goleiros negros não eram competentes o suficiente para defenderem a seleção brasileira; ou seja, esses arqueiros passaram a ser preteridos em relação aos goleiros brancos. Além disso, legitimou-se a concepção de que negros não possuíam estrutura emocional suficiente para embates de grande envergadura (Skolaude, 2015, p. 15).

O futebol ainda é carregado de ambuiguidade, uma vez que ele é visto como fator que une a sociedade, mas, ao mesmo tempo, foi construído promovendo desigualdade e exclusão. Luccas (1998) nos lembra que a independência estrutural e institucional pressuposta no futebol é falseadora. Ela encobre as relações de nepotismo, favorecimentos políticos, má administração do dinheiro e corrupção no esporte, da mesma forma como envolvem outras instituições sociais. "Neste momento de transformações estruturais pelas quais passa o futebol é bastante paradigmática a referência saudosista ao passado" (Luccas, 1998, p. 43).

Como pudemos acompanhar pela pesquisa, "a história do futebol é permeada pelas mesmas desigualdades, exclusões sociais e políticas diversas que caracterizam a sociedade brasileira nestes últimos cem anos" (Luccas, 1998, p. 42). As(os) psicólogas(os) devem conhecer sobre as políticas de identidade e as teorias que tratam da formação das identidades e, por esse motivo, abordaremos a temática no próximo item.

\section{Identidade étnico racial e sofrimento psíquico}

A construção social, cultural e política faz com que o indivíduo desenvolva uma identificação com grupo racial ou étnico. Está ligado diretamente com as experiências de vida, educação e socialização no meio onde o sujeito está inserido "e também com a consciência adquirida diante das prescrições sociais raciais ou étnicas, racistas ou não, de uma dada cultura" (Oliveira, 2004, p. 57). Ciampa (1987), citado por 
Pinto e Ferreira (2014, p. 261), tem a visão de que a identidade está em constante mudança, sendo produto da relação entre história pessoal, contexto sócio histórico e objetivos do sujeito.

O CFP (2017) afirma que o negro que está inserido em um grupo racial de negros tem a possibilidade de construir sua identidade individual e coletiva de forma beneficente para sua saúde mental. Isto devido aos estímulos e laços que ele vai desenvolver no grupo, que pode vir a proporcionar uma visão positiva a respeito de sua própria identidade negra. Ao construir uma identidade racial coletiva e pessoal, o negro tem um recuso que potencializa a estruturação da sua autoestima e autoconfiança.

Segundo a concepção de Melo (2015, p. 3), "o indivíduo é construído nas interações sociais, espaços de socialização que influenciam formas de agir, ser, viver e pensar o mundo, construir, produzir símbolos, lutar, resistir". O indivíduo possui uma construção histórica e tem uma significância na construção da sua identidade.

No Brasil é extremamente complicado assumir uma identidade racial negra, visto ser este um processo difícil e doloroso devido à escassez de referências negras com visibilidade e sucesso, e mesmo quando aparecem, não existe um respeito à diversidade étnico racial. Oliveira (2004) afirma que desconhece estudos firmes sobre identidade racial/étnica no Brasil.

Silva (2000, p. 74) afirma que "é simplesmente o que é”, nesta perspectiva, quando alguém afirma "sou negro", se afirma com uma identidade, negando as outras possíveis identidades não pertencentes a ele. Por exemplo, ao se afirmar negro, automaticamente nega ser branco, pardo, amarelo e assim por diante. Melo (2015), destaca que, além de se constituírem de forma dependente, identidade e diferença são criações linguísticas que se manifestam no senso comum. Esse fenômeno acontece "a partir do reconhecimento de alguma origem comum ou de características comuns ou mesmo da crença em um mesmo ideal, valor ou traço" (Melo, 2015, pp. 3-4). Portanto as identidades englobam relações de poder, resultado de hierarquias, disputas e imposição, procurando afirmar recursos simbólicos da sociedade, se transformando em uma produção discursiva usada como natural na linguagem.

No que diz respeito à identidade negra, desde que o Brasil começou a se formar como sociedade percebe-se que o indivíduo negro se afasta de si.
Como Melo (2015, p. 5) afirma, existe "um desejo de ser branco", além de existir uma interiorização de estigmas e de diversos sentimentos, tais como vergonha, humilhação, sensação de inferioridade.

A maioria da população brasileira, negra e branca, introjetou o ideal do branqueamento. Esse ideal, inconscientemente, interfere no processo de construção da identidade da pessoa negra, pois o sentimento de solidariedade e pertencimento de grupo entre a população negra acaba por se enfraquecer (Pinto \& Ferreira, 2014, p. 262).

De acordo com Munanga, citado por Pinto e Ferreira (2014), a ideia do branqueamento tem impacto diretamente na formação da autoestima do negro. O sujeito negro interioriza todo preconceito dirigido a ele ou a cor, desenvolvendo condutas de identificação com os valores da cultura que predomina, que é a do branco. O preconceito racial, em qualquer parte do contexto social, reafirma o lugar metafórico do negro na sociedade, criando uma negação e inferioridade do negro.

Sendo assim, os estigmas, situações de racismo e discriminação que acontecem no dia a dia, podem influenciar negativamente na produção do autoconhecimento do negro, uma vez reconhecido que tudo isso são definições que não condizem com a realidade. Melucci (2004) citado por Melo (2015, p. 4) fala a respeito "da identidade como dependente do retorno de informações vindas dos outros". Sendo assim, o negro, tendo lugar de inferioridade numa sociedade racista, terá de um outro uma visão contaminada pelo preconceito.

\section{Orientações do Conselho Federal de Psicologia (CFP)}

O CFP lançou, em 2017, uma cartilha com referências técnicas para orientar a categoria a respeito de como a psicologia poderia contribuir para entender e erradicar o racismo. A cartilha define três formas de o racismo impactar a subjetividade do negro, dependendo da maneira como o sujeito lida com a discriminação. São elas: crescimento e questionamento; utilização de mecanismos psíquicos defensivos contra o racismo; e dilaceramento psíquico.

A primeira é quando a pessoa tem percepção de como o racismo a impactou e transforma isso 
em maneiras sociais e psicológicas para combatê-lo. Ela poderá alcançar um crescimento, potencializando aquilo que sofreu e se engajando na luta contra o racismo, seja por meios políticos, laços familiares e círculo de amigos (Conselho Federal de Psicologia, 2017, p. 58). O ex árbitro Marcio Chagas é um exemplo disso quando diz que resolveu denunciar o racismo mesmo que isso lhe custasse o prejuízo no trabalho. Sua fala é marcante e doída e por isso decidimos trazê-la na íntegra:

Eu posso até me prejudicar no trabalho, mas resolvi comprar a briga porque . . . nos fóruns que reúnem negros, costumamos dizer que os racistas podem nos fazer duas coisas: ou eles nos matam ou eles nos adoecem. Eu me recuso a morrer ou adoecer. Prefiro lutar. Quando esses ataques acontecem, minha mulher, que é negra, me dá a força que ela consegue. Ela sabe muito bem o que é isso. Meus filhos ainda não sabem. Eu fortaleci a consciência da minha negritude principalmente pelo rap, ouvindo aquela música, analisando aquela letra e me identificando com aquela situação retratada (Silva, 2019, p. 1).

Um segundo impacto para a subjetividade (apontado na cartilha) é a utilização de mecanismos psíquicos inconscientes para se defender do racismo. Neste caso a tendência é que a vítima negue que a atitude do outro foi preconceituosa, para não lidar com os sentimentos de discriminação (Conselho Federal de Psicologia, 2017). Tendemos a interpretar o caso de Sergio Camargo, presidente da Fundação Palmares como sendo dessa natureza, pois toda sua negação do racismo e ações que contrariam os interesses do povo negro só pode ter essa explicação.

E por último, o dilaceramento psíquico, que tem um caráter mais desestabilizador no sujeito, ou seja, "aqueles em que o efeito do racismo é vivido como catastrófico, precisam de uma gama variada de apoio para se refazer do trauma vivido" (Conselho Federal de Psicologia, 2017, p. 59). O sujeito pode recorrer à terapia individual, coletiva, buscar políticas públicas que o auxiliem no processo de reconstrução psíquica. No que diz respeito à utilização dos mecanismos psíquicos defensivos e dilaceramento psíquico, Gonçalves Filho (1998), citado pelo Conselho Federal de Psicologia (2017, p. 59), afirma que, "em função do jugo racista, como defesa a esse jugo, o sujeito pode tentar afastar-se de situações que possam aproximá-lo de sua negritude, seja do contato com outros negros(as), seja dos sinais corpóreos que indicam sua condição racial-fenotípica”.

Não podemos desconhecer que esse processo é também um tipo de defesa contra a humilhação política racista historicamente vivida, o que causa muito sofrimento. Essa angústia é ancestral pois "foi vivida por ele antes e por seus antecedentes e os antecedentes de seus antecessores" (Gonçalves Filho, citado por Conselho Federal de Psicologia, 2017, p. 59).

A cura da consequência de um ato racista necessita de intervenção tanto para quem comete, quanto para quem sofre. É preciso criar meios em que o(a) negro(a) possa se reforçar psíquica e politicamente, e conscientizar os brancos do seu papel nesta construção étnico racial. De acordo com a cartilha do CFP (2017, p. 60) é preciso que os brancos se conscientizem do "privilégio que possuem pois isso perpetua a violência entre os negros(as)".

Existe um alto número de jogadores negros, que mesmo depois de construírem uma carreira de expressão no esporte sofrem com o preconceito, vindo de cânticos de torcida ou ações de instituições e outros jogadores. Embora "nenhuma empresa brasileira declare por escrito: "não aceitamos negras(os) para o cargo de chefia", (Conselho Federal de Psicologia, 2017, p. 111), dentro dos clubes e federações é baixo o número de negros como técnicos, diretores e presidentes de clubes, árbitros e demais profissões dentro deste esporte. $\mathrm{O}$ resultado disso é a quase invisibilidade do negro nos lugares de comando no futebol. No próximo item abordaremos o papel e os desafios da psicologia no campo do esporte, abordando as ações que devem ser norteadoras de uma clínica ético-politicamente comprometida com a erradicação do racismo no esporte e, consequentemente, no futebol.

\section{A construção de uma psicologia clínica para o esporte comprometida com a erradicação do racismo}

A questão étnico racial ficou por muito tempo invisível ao interesse da psicologia. Só em 2017 o CFP lançou uma cartilha com referências técnicas à categoria, embora desde 2010 um coletivo de psicólogos(as) tenha formado uma rede de pesquisadores da questão racial em psicologia. Como a psicologia é uma ciência que estuda a subjetividade humana, ela pode e deve "fornecer subsídios consistentes para explicar 
fenômenos como apatia social, vínculos, desenvolvimento psicossocial e os efeitos psíquicos do racismo nas relações humanas" (Mäder, 2016, pp. 15-16).

Em relação ao esporte temos um marco da psicologia no Brasil que é a instituição das especialidades no Brasil com a resolução 014/00. Mesmo depois da Psicologia do Esporte (PE) ter se tornado uma especialidade da psicologia, indo para além de sempre ter sido uma das ciências do esporte, temos, de acordo com os estudos de Myotin (2018), sobre a psicologia do esporte no estado de Minas Gerais, ínfima produção de conhecimento sobre o que acontece no esporte por parte das faculdades de psicologia. $\mathrm{O}$ estudo de Myotin (2018) mostrou que as faculdades de educação fisica são hegemônicas na produção de conhecimento na PE, dando preferência aos estudos sobre aspectos relativos à melhoria da performance no esporte de alto rendimento. Daí que o racismo no esporte ainda não foi investigado como deveria pela PE também.

Concordamos com a cartilha do CFP (2017, p. 214) quando alega que "em sociedades desfiguradas por séculos de discriminação generalizada, não é suficiente que as instituições se abstenham de discriminar, sendo necessária uma ação positiva comprometida com a promoção da igualdade". A questão é da adoção de uma política afirmativa que englobe a inclusão e ascensão da igualdade. Necessita de uma atenção e ação constante das instituições contra as atitudes que se dizem neutras ou sem intenção de discriminar. Assim é possível enfrentar e combater o preconceito que vem se velando cada dia mais.

É preciso fazer a distinção entre a ação afirmativa e os comportamentos atuante das instituições que favorecem a criação de condições que permitam a todos beneficiar-se da igualdade de oportunidade e de tratamento. A ação afirmativa visa eliminar qualquer fonte de discriminação, direta ou indireta, criando por exemplo, cotas raciais na contratação de funcionários. Isso tem acontecido atualmente quando há concursos públicos com reserva de vagas para a população negra. "Apesar do número de ações afirmativas efetivamente relacionadas à política pública ou privada ser pequeno, a incorporação dela é facilmente percebida, assim como seu efeito" (Conselho Federal de Psicologia, 2017, p. 114).

Essas ações afirmativas podem ser pensadas e colocadas em prática a partir do diagnóstico institucional. Considerando o contexto brasileiro, é preciso que as pessoas, e principalmente os profissionais - os da psicologia principalmente - tenham ambientes em que possam pensar a respeito da identidade negra. "É importante que as(os) profissionais façam a reflexão sobre si próprios, como sujeitos constituídos em uma sociedade cujo imaginário social demarca a(o) negra(o) em um lugar inferior, oprimido e menos valorizado, ocupando subempregos ou restritos a arte e esporte" (Conselho Federal de Psicologia, 2017, p. 115).

Segundo Oliveira e Nascimento (2018), a cartilha do CFP ainda não é capaz de ampliar o olhar da psicologia clínica em relação ao sofrimento derivado do preconceito racial, porque no que tange aos aspectos epistemológicos das construções da psicologia para a dimensão emocional, individual (singular) e subjetiva - no caso, a psicologia clínica - não há bases teóricas que possam referendar a escuta clínica "do sofrimento psíquico decorrente da violência traumática de uma sociedade racista e racializada em todos os seus âmbitos" (Oliveira \& Nascimento, 2018, pp. 225-226).

A cartilha chama a tenção para o fato de ser o homem e o "aparelho psíquico" efeitos da realidade onde vive e que o psicólogo e profissional de saúde mental precisa considerar os aspectos históricos da construção da sociedade como um todo. "Banhado pela cultura e pela etnicidade, que também inclui a racialidade, o racismo, e toda gama de dificuldades sociais emocionais" (Oliveira \& Nascimento, 2018, pp. 226-227).

Em nossa opinião, a Psicologia do Esporte tem um grande desafio pela frente, já que é necessário também "inventar" uma clínica psicológica capaz de acolher e escutar o sofrimento psíquico advindo do racismo e das perversões de um contexto de civilização como a brasileira. Reconhecemos que a história da PE, enquanto uma especialidade da Psicologia, merece tratamento teórico mais pormenorizado, mas como esse não é nosso foco nesse momento, deixaremos marcado nosso compromisso de abordá-lo em outro trabalho.

\section{Conclusão}

O sujeito negro enfrenta, ao longo da história, a dificuldade de garantir seus direitos e a construção e afirmação de suas subjetividades sem uma conotação pejorativa. Há diversos fatores que levam a tal dificuldade, mas estão ligados à construção histórica do Brasil, que tem uma construção cultural e ideológica 
que rebaixa o negro. O tráfico negreiro e a escravidão, como já contextualizado neste estudo, reafirmam essa ideia. No Brasil, existe a ideia de que pretos e brancos vivem harmonicamente, caracterizando uma ideia de democracia racial, em que todos têm direitos iguais (Melo, 2015, p. 4).

Como demonstramos nesta pesquisa, o racismo apresenta diversas facetas, que podem ter diversas consequências sobre a vida do sujeito, além do adoecimento da pessoa que sofreu violência, as consequências podem se estender até a família.

A formação curricular do aluno de psicologia precisa apresentar as bases epistemológicas que apresentem contexto sócio histórico, escravidão, política da colonização e povos africanos, o genocídio de negros e indígenas, bem como a escravidão. Toda essa história deixou marcas que estruturam a base do pensamento psiquismo - de negros e brancos e isso precisa ser de conhecimento dos profissionais da Psicologia.

Existe um alto número de jogadores negros, que mesmo depois de construírem uma carreira de expressão no esporte sofrem com o preconceito, vindo de cânticos de torcida ou ações de instituições e outros jogadores. Embora o racismo não apareça de forma evidente, já que nenhuma empresa declararia não aceitar negros em seus quadros para cargos de comando, podemos contar nos dedos o número de negros que estão nesses dentro das federações como gerentes, diretores e presidentes de clubes. Mas também dentro das quatro linhas do campo do futebol não vemos técnicos, árbitros e demais profissionais como médicos, fisioterapeutas e psicólogos atuando. O resultado disso é a quase invisibilidade do negro nos lugares de comando no futebol. Por esse motivo, é necessária a implantação de políticas afirmativas visando democratizar a participação de pessoas pretas em cargos de gestão no esporte, por exemplo.

Pode-se assim concluir que a construção do futebol no Brasil é marcada pelo preconceito racial. É evidente que a discriminação traz consequências à construção da identidade do negro, uma vez que ainda nos dias de hoje é visto como inferior em determinados contextos sociais. No Brasil, ainda se perpetua a ideia de branqueamento, o que leva muitos sujeitos a construírem uma identidade baseada no sujeito branco.

Segundo o CFP (2017, p. 113), um plano de intervenção dentro da instituição para o combate do preconceito racial necessita "refletir nos códigos de conduta, na missão da instituição, nos princípios; enfim, na maneira como a instituição se posiciona, interna e externamente". No contexto do futebol, as notas de repúdio, punições vindas dos clubes ou instituições máximas que coordenam o futebol são exemplos dessas medidas.

A cartilha do CFP traz contribuições relevantes para a atuação do psicólogo, contudo, ainda é preciso pensar uma clínica para a Psicologia do Esporte que enxergue os impactos do preconceito sofrido além de um mero sofrimento subjetivo. Desta forma, é preciso considerar o contexto sócio histórico do sujeito e seu lugar de fala. Para isso, é necessário um diálogo da psicologia com todas as áreas de ciências humanas, para ter ferramentas para fazer uma leitura dos impactos do racismo na subjetividade do jogador de futebol negro. Só a partir da interdisciplinaridade podemos trazer elementos que agreguem à construção de uma clínica voltada para as relações raciais.

Durante a pesquisa bibliográfica não foram encontrados estudos dentro da especialidade Psicologia do Esporte a respeito do impacto do racismo na subjetividade do jogador negro ou qualquer outro trabalhador do esporte, e nem sobre as formas de combate do preconceito no âmbito esportivo. Na mídia, é possível achar reportagens e matérias a respeito disso, conforme citado na introdução do trabalho. Acreditamos que, se utilizados como fatos para argumentar durante a produção do trabalho, poderiam fragilizar o estudo.

Como último ponto, a cartilha do CFP afirma que, para que uma intervenção aconteça de forma efetiva, é preciso identificar ações feitas pelas instituições que podem ter causado desigualdade racial. Para que isso aconteça o CFP orienta que seja obrigatório ter nos formulários, fichas cadastrais das(os) usuárias(os), espaço para identificação do quesito cor, "de modo a poder visualizar o perfil da população atendida, bem como a forma com que as ações alcançam os diferentes grupos raciais" (Conselho Federal de Psicologia, 2017, p. 116).

Sendo assim, é importante entender até onde serviços como promoção de saúde, educação, saneamento alcançam as populações de diferentes etnias. Para que desta forma o profissional entenda melhor os problemas e pontos críticos para executar seu trabalho.

Independentemente de como começará o trabalho do psicólogo atuante na instituição, seja pelo levantamento do quesito raça/cor, diagnóstico da discriminação ou pela reflexão dos profissionais e 
gestores a respeito da discriminação racial, concordamos com o CFP (2017, p. 117) que "o fato é que todos esses passos precisam ser contemplados para que o resultado seja a criação de serviços públicos e privados como ações afirmativas e, como tal, que sejam equânimes em sua composição".

É preciso que todos na instituição, seja pública ou privada, independentemente da hierarquia, estejam aptos a debater sobre o racismo. Com as orientações da cartilha do conselho de 2017 é possível pensar a atuação e colaboração do psicólogo em não somente conscientizar e combater o racismo, mas também uma atuação que possa entender o sofrimento que o preconceito causa no jogador de futebol negro. Ainda que seja uma área em que alguns negros possuem uma grande visibilidade, salários altos e grande influência. Mas, ainda assim, enfrentam o preconceito racial.

Em tempos de retração de direitos, nossa categoria profissional terá que estar em vigília para evitar que tudo que já se foi pensado para o combate do racismo seja negligenciado e de novo se torne invisível na produção cientifica.

\section{Referências}

Albuquerque, W., \& Filho, W. (2006). Uma história do Brasil. Fundação Cultura dos Palmares.

Cervo, A. L., \& Bervian, P. A. (2002). Metodologia científica. Prentice Hall.

Conselho Federal de Psicologia. (2017). Relações raciais: Referências técnicas para atuação de psicólogas/os.

Luccas, A. (1998). Futebol e torcidas: Um estudo psicanalítico sobre o vínculo social [Dissertação de mestrado, Pontifícia Universidade Católica de São Paulo].

Mãder, B. (2016). Psicologia e relações étnico-raciais: diálogos sobre o sofrimento psíquico causado pelo racismo. Conselho Regional de Psicologia - 8a Região.

Maximo, J. (1999). Memórias do futebol brasileiro. Estudos Avançados, 13(37), 179-188. https://doi.org/10.1590/ S0103-40141999000300009.

Melo, D. J. L. (2015). A produção social da identidade étnico-racial e o "lugar" do Negro no Brasil: Entre construções e desconstruções [manuscrito não-publicado]. Universidade Federal do Maranhão.

Myotin, E. (2018). Psicologia do Esporte: Produção científica em Pós-graduação em Educação Física e Psicologia de Minas Gerais (1980-2012) [Dissertação de mestrado, Universidade Federal de Minas Gerais]. Repositório UFMG. https:// repositorio.ufmg.br/handle/1843/BUOS-B4TFZ5

Oliveira, F. (2004). Ser negro no Brasil: Alcances e limites. Estudos Avançados, 18(50), 57-60. https:// doi.org/ 10.1590/ S0103-40142004000100006

Oliveira, R., \& Nascimento, M. (2018). Psicologia e relações raciais: Sobre apagamentos e visibilidades. Revista da $A B P N$, 10(24), 216-240. http://www.abpnrevista.org.br/revista/index.php/revistaabpnl/article/view/582

Pinto, M., \& Ferreira, R. (2014). Relações raciais no Brasil e a construção da identidade da pessoa negra. Pesquisas e Práticas Psicossociais, 2(9), 257-266.

Pires, B. (2017, 20 de novembro). No futebol, a face mais explícita do racismo que "faz parte do jogo". El País. https://brasil.elpais.com/brasil/2017/11/16/deportes/1510857476_990270.html

Psicólogos negros formam rede de pesquisadores da questão racial de psicologia. (2010, dezembro). Jornal do Conselho Federal de Psicologia. https://site.cfp.org.br/wp-content/uploads/2012/03/jornal_federal_99.pdf

Silva, T. T. (2000) A produção social da identidade e da diferença. In T. T. Silva (Org.), Identidade e diferença (pp. 73-102). Vozes.

Silva, M. C. (2019, 29 de abril). Matar negro é adubar a terra: Comentarista de arbitragem da Globo denuncia agressões racistas que ouviu no campo e na cabine. UOL Esporte. https://esporte.uol.com.br/reportagens-especiais/ marcio-chagas-denuncia-racismo/index.htm\#matar-negro-e-adubar-a-terra

Skolaude, M. (2015). Raça e racismo na história do futebol brasileiro. In M. L. Silva (Org.), 21 textos para discutir preconceito em sala de aula (pp.112-117). Gazeta; EDUNISC.

Souza, J. (2017). A elite do atraso: da escravidão à Lava-Jato. Leya. 
Fábio Henrique Alves da Silva

Psicólogo formado pela Pontifícia Universidade Católica de Minas Gerais, Betim - MG. Brasil.

E-mail: fabbioalves@outlook.com

(1) https://orcid.org/0000-0003-4098-2769

\section{Paula Ângela de Figueiredo e Paula}

Professora adjunta da Pontifícia Universidade Católica de Minas Gerais, doutora em psicologia social, mestre em treinamento esportivo e graduada em psicologia pela Pontifícia Universidade Católica de Minas Gerais, Betim - MG. Brasil.

E-mail: pauladepaula@uol.com.br

(10) https://orcid.org/0000-0002-0250-0055

Endereço para envio de correspondência:

Rua Vitória Regia, 228, Ponte Alta. CEP: 32605600. Betim - MG. Brasil.

Recebido 17/10/2019

Aceito 18/10/2019

Received 10/17/2019

Approved 10/18/2019

Recibido 17/10/2019

Aceptado 18/10/2019

Como citar: Silva, F. H. A., \& Paula, P. A. F. (2020). Os impactos do racismo na subjetividade do jogador de futebol negro. Psicologia: Ciência e Profissão, 40 (n.spe), 1-12. https://doi.org/10.1590/1982-3703003230122

How to cite: Silva, F. H. A., \& Paula, P. A. F. (2020). The impacts of racism on the subjectivity of black soccer players. Psicologia: Ciência e Profissão, 40 (n.spe), 1-12. https://doi.org/10.1590/1982-3703003230122

Cómo citar: Silva, F. H. A., \& Paula, P. A. F. (2020). Los impactos del racismo en la subjetividad de los futbolistas negros. Psicologia: Ciência e Profissão, 40 (n.spe), 1-12. https://doi.org/10.1590/1982-3703003230122 